\title{
Reduced Corneal Endothelial Cell Density in Patients With Dry Eye Disease
}

\section{Citation}

Kheirkhah, Ahmad, Ujwala S. Saboo, Tulio B. Abud, Thomas H. Dohlman, Michael A. Arnoldner, Pedram Hamrah, and Reza Dana. 2015. "Reduced Corneal Endothelial Cell Density in Patients With Dry Eye Disease." American Journal of Ophthalmology 159 (6) (June): 1022-1026.e2. doi:10.1016/j.ajo.2015.03.011.

\section{Published Version}

10.1016/j.ajo.2015.03.011

\section{Permanent link}

http://nrs.harvard.edu/urn-3:HUL.InstRepos:34854273

\section{Terms of Use}

This article was downloaded from Harvard University's DASH repository, and is made available under the terms and conditions applicable to Open Access Policy Articles, as set forth at http:// nrs.harvard.edu/urn-3:HUL.InstRepos:dash.current.terms-of-use\#OAP

\section{Share Your Story}

The Harvard community has made this article openly available.

Please share how this access benefits you. Submit a story.

\section{Accessibility}


Published in final edited form as:

Am J Ophthalmol. 2015 June ; 159(6): 1022-1026.e2. doi:10.1016/j.ajo.2015.03.011.

\title{
Reduced Corneal Endothelial Cell Density in Patients with Dry Eye Disease
}

\author{
Ahmad Kheirkhah, Ujwala S Saboo, Tulio B Abud, Thomas H Dohlman, Michael A \\ Arnoldner, Pedram Hamrah, and Reza Dana \\ Cornea and Refractive Surgery Service, Massachusetts Eye and Ear Infirmary, Department of \\ Ophthalmology, Harvard Medical School, Boston, Massachusetts, USA
}

\begin{abstract}
Purpose-To evaluate corneal endothelial cell density (ECD) in patients with dry eye disease (DED) compared to an age-matched control group.
\end{abstract}

Design-Cross-sectional, controlled study

Methods-This study included 90 eyes of 45 patients with moderate-to-severe DED (53.7 \pm 9.8 years old) and 30 eyes of 15 normal controls ( $50.7 \pm 9.8$ years old). All subjects had a complete ophthalmic evaluation including symptom assessment using the Ocular Surface Disease Index (OSDI) and corneal fluorescein staining. In addition, laser scanning in vivo confocal microscopy was performed to measure the density of the following parameters in the central cornea: endothelial cells, subbasal nerves, and subbasal immune dendritic cells.

Results—Corneal ECD was significantly lower in the DED group $\left(2595.8 \pm 356.1 \mathrm{cells} / \mathrm{mm}^{2}\right)$ than in the control group $\left(2812.7 \pm 395.2\right.$ cells $\left./ \mathrm{mm}^{2}, \mathrm{P}=0.046\right)$. The DED group showed significantly lower corneal subbasal nerve density $\left(17.1 \pm 6.9 \mathrm{~mm} / \mathrm{mm}^{2}\right)$ compared to the control group $\left(24.7 \pm 4.4 \mathrm{~mm} / \mathrm{mm}^{2}, \mathrm{P}<0.001\right)$. Dendritic cell density was significantly higher in the DED group than in the controls ( $111.7 \pm 137.3$ versus $32.0 \pm 24.4$ cells $/ \mathrm{mm}^{2}$, respectively, $\left.\mathrm{P}=0.002\right)$. There were statistically significant correlations between corneal ECD and dry eye severity parameters including the OSDI score $\left(\mathrm{r}_{\mathrm{s}}=-0.26, \mathrm{P}=0.03\right)$, and corneal fluorescein staining $\left(\mathrm{r}_{\mathrm{s}}=\right.$ $-0.28, \mathrm{P}=0.008)$.

(C) 2015 Published by Elsevier Inc.

Corresponding Author: Reza Dana, MD, MPH, MSc, Massachusetts Eye and Ear Infirmary, 243 Charles Street, Boston, MA 02114, USA, Tel +1 617573 4439, Fax +1 617573 4300, Reza_Dana@meei.harvard.edu.

DISCLOSURE:

Financial Disclosures: AK, US, TA, TD, and MA: None. PH is a consultant for Allergan (Irvine, California). RD is a consultant for Eleven Biotherapeutics (Cambridge, Massachusetts), Alcon (Fort Worth, Texas), Allergan (Irvine, California), Bausch \& Lomb (Bridgewater, New Jersey), and Genentech (San Francisco, California). RD also holds equity at Eleven Biotherapeutics (Cambridge, Massachusetts).

Contributions to Authors: Design and conduct of the study (AK, PH, RD); Analysis and interpretation (AK, RD), Data collection (AK, US, TA, TD, and MA), Writing (AK), Critical revision (PH, RD), Final approval (RD).

Publisher's Disclaimer: This is a PDF file of an unedited manuscript that has been accepted for publication. As a service to our customers we are providing this early version of the manuscript. The manuscript will undergo copyediting, typesetting, and review of the resulting proof before it is published in its final citable form. Please note that during the production process errors may be discovered which could affect the content, and all legal disclaimers that apply to the journal pertain. 
Conclusions-There is a significant reduction in corneal ECD in DED which correlates with clinical severity of the disease.

\section{INTRODUCTION}

Dry eye disease (DED) is one of the most commonly seen conditions in ophthalmic practice, affecting 5-35\% of the general population. ${ }^{1-3}$ It has been shown that the underlying pathogenic mechanisms for DED at the level of the ocular surface relate to tear hyperosmolarity, tear film instability, and associated ocular surface inflammation. ${ }^{4}$ In addition, there is ample evidence that innervation of the ocular surface plays a critical role in maintenance of a normal tear film, ${ }^{4}$ and disruption of the nerves leads to reduced tear secretion and resultant DED. ${ }^{5,6}$ In fact, reduced corneal nerve density has been demonstrated in patients with DED using in vivo confocal microscopy (IVCM). ${ }^{7-11}$

The cornea has the highest nerve density in the body. ${ }^{12,13}$ In addition to providing sensation and regulating tear secretion, these nerves have been shown to play a significant role in maintaining corneal health and function. ${ }^{13,14}$ Although the trophic function of the corneal nerves on the epithelium has been established, ${ }^{14,15}$ this supportive role may not be limited to the epithelium. This has been suggested by recent data showing the presence of neurotrophic factors in all corneal layers, ${ }^{16,17}$ as well as significant changes in all these layers, including the endothelium, in cases with neurotrophic keratopathy. ${ }^{18,19}$

As corneal nerves have been shown to be decreased in DED, ${ }^{7-11}$ we hypothesized that this would result in reduced corneal endothelial cell density (ECD). Therefore, this study was designed to evaluate ECD in patients with DED compared to an age- and gender-matched control group and to correlate this parameter with the clinical severity of the disease.

\section{MATERIALS AND METHODS}

This cross-sectional study included 90 eyes of 45 patients with DED (the DED group) and 30 eyes of 15 normal age- and gender-matched controls (the control group), which were all recruited from the Cornea and Refractive Surgery Service, Massachusetts Eye and Ear Infirmary, Boston, Massachusetts. All subjects signed an informed consent form prior to participation in the study. The protocol of the study was approved by the Human Studies Committee of the Massachusetts Eye and Ear Infirmary, Boston, Massachusetts, and the research was conducted in accord with the requirements of the Health Insurance Portability and Accountability Act (HIPAA) and the tenets of the Declaration of Helsinki.

The DED group included patients with symptoms of DED who had an Ocular Surface Disease Index (OSDI) score greater than 22 and corneal fluorescein staining of 4 or more in National Eye Institute [NEI] grading scale, which is approximately equivalent to 2 or more in Oxford scheme for grading of staining. Patients with a history of increased intraocular pressure, previous contact lens wear, history of use of any medications known to have corneal toxicity, previous ocular surgery, any corneal disease including herpetic keratitis, or endothelial guttae were excluded. Individuals in the control group had normal healthy corneas and did not have any symptoms of DED with a normal tear meniscus and no corneal or conjunctival staining. Individuals with a history of contact lens wear were also excluded 
from the control group. Individuals with diabetes mellitus were excluded from both DED and control groups.

All participants in the DED group had a complete ophthalmic evaluation, which included the following: OSDI questionnaire; measurement of the best corrected visual acuity and intraocular pressure; slit-lamp biomicroscopy to assess corneal fluorescein staining (NEI scale, 0-15), conjunctival staining with lissamine green (NEI scale, 0-18), and tear break-up time (TBUT); and Schirmer test with anesthesia.

\section{In Vivo Confocal Microscopy}

To measure the density of corneal endothelium, subbasal immune dendritic cells, and subbasal nerves, the central cornea in both eyes of all subjects were evaluated by IVCM using a Heidelberg Retina Tomograph 3 with the Rostock Cornea Module (Heidelberg Engineering, Heidelberg, Germany). This machine, which utilizes a 670-nm diode laser, provides digital images from the full thickness of the cornea through sequences consisting of 100 images per each one. Each image represents a coronal section of $384 \times 384$ pixels which is equivalent to $400 \times 400 \mu \mathrm{m}$ of the cornea.

The details of imaging with IVCM have been described before. ${ }^{20}$ Briefly, a disposable sterile polymethylmethacrylate cap (Tomo-Cap; Heidelberg), filled with a layer of $0.3 \%$ hypromellose (GenTeal gel; Alcon, Fort Worth, Texas) in the bottom, was mounted in front of the cornea module. After topical anesthesia by $0.5 \%$ proparacaine hydrochloride (Alcaine; Alcon, Fort Worth, Texas), a drop of $0.3 \%$ hypromellose (GenTeal gel) was instilled in the eye. One drop of $0.3 \%$ hypromellose was also placed on the outside tip of the cap to improve optical coupling. Then, the module was manually advanced until the gel contacted the central surface of the cornea. After visualization of the superficial corneal epithelium, the focus was advanced to the corneal subbasal layer, usually at the depth of 50$80 \mu \mathrm{m}$. After obtaining 3-4 sequence scans of the subbasal layer in various locations in the central cornea, the focus was then advanced through the full thickness of the stroma and, finally, to the endothelium. Again, multiple locations in the central cornea were imaged using sequence scans of the endothelium.

The IVCM images from the endothelial layer were chosen to measure ECD using the variable-frame method. For this, the image was imported to the ImageJ software (http:// imagej.nih.gov/ij/). After adjusting for pixel/micron ratio, the Polygon Selection tool of ImageJ was used to mark the borders of the cells in the area of the image which had good quality with no distortion. Then, this selected area was measured in $\mathrm{mm}^{2}$. The cells present in the selected area were then counted using Cell Counter plug-in of the ImageJ, and expressed as cells $/ \mathrm{mm}^{2}$. For each eye, two IVCM images of central corneal endothelium were measured and then averaged. Two independent observers measured ECD for each image and the average of the measurements by the observers was used for the analysis.

In addition to measurement of ECD, the IVCM images of the subbasal layer were used to measure the density of subbasal nerves and epithelial immune dendritic cells, as previously described. ${ }^{20}$ To do so, three good-quality representative images from different locations of subepithelial layer, which is located immediately at or posterior to the basal epithelial layer, 
were chosen for analysis. Dendritic cells were identified by their morphology of bright dendritiform structures with cell bodies that were different from linear structures of corneal nerves. ${ }^{20}$ For calculating the density of subbasal dendritic cells, ImageJ software (National Institutes of Health, USA) was used. To do this, the Cell Counter plug-in of the ImageJ was used to count the number of dendritic cells in the entire frame $\left(160,000 \mu^{2}\right)$. The average count of three different IVCM images was then calculated and expressed as cells $/ \mathrm{mm}^{2}$. To measure subbasal nerve density, the nerves were traced using NeuronJ software (http:// www.imagescience.org/meijering/software/neuronj/), which is a semi-automated nerve analysis plug-in program of ImageJ. Nerve density was measured by tracing all visible nerve fibers in the image and calculating the length of the nerve fibers in millimeters. Then, the average nerve density of three different IVCM images was calculated and expressed as $\mathrm{mm} / \mathrm{mm}^{2}$. All measurements were performed by two independent observers and the average values were used for the analysis.

\section{Statistical Analysis}

Statistical analysis was performed with SPSS version 20 (SPSS Inc., Chicago, IL). The normality of the data was first assessed using the Shapiro-Wilk test. Due to non-normal distribution of the data, the Mann-Whitney U test was used to compare the age between the DED and control groups. To compare the densities of endothelial cells, nerves, and dendritic cells between the groups, mixed model analysis was used to compensate for including both eyes of each individual. The confounding effect of age was also considered in this model. Furthermore, the correlations between the ECD and the clinical parameters were investigated using the Spearman's test. To correlate the ECD with the OSDI scores in the DED group, the ECD values of both eyes were averaged. $P$ values of less than 0.05 were considered as statistically significant.

To determine the sample size, a pilot study was performed on 66 eyes with DED and 20 eyes of normal subjects. The ECD was found to be $2633 \pm 399 \mathrm{cell} / \mathrm{mm}^{2}$ in the DED group and $2866 \pm 367 \mathrm{cell} / \mathrm{mm}^{2}$ in the control group. Therefore, a difference of 233 with an average standard deviation of 383, a 0.05 two-sided significance level, and $80 \%$ power were used to calculate the study sample size which resulted in 116 . Thus, for our study a sample size of 120 eyes was employed which were divided between the DED and the control groups in a ratio of $3: 1$.

\section{RESULTS}

This study included 90 eyes of 45 patients with DED (28 women and 17 men, mean age: $53.7 \pm 9.8$ years, range: $34-71$ years) and 30 eyes of 15 subjects in the control group ( 8 women and 7 men, mean age: $50.7 \pm 9.8$ years, range: $25-64$ years). There were no significant differences found between the two groups in terms of age $(\mathrm{P}=0.15)$ or gender $(\mathrm{P}=0.40)$. Patients with DED had a mean OSDI score of $61.5 \pm 20.8$, a mean score for corneal fluorescein staining of $7.0 \pm 3.4$, a mean lissamine green staining score of $2.0 \pm 2.9$, a mean TBUT of $3.2 \pm 2.8$ seconds, and a mean Schirmer score of $6.7 \pm 6.8 \mathrm{~mm}$.

Mixed model analysis demonstrated that after adjustment for age the mean ECD was significantly lower in the DED group $\left(2595.8 \pm 356.1 \mathrm{cells} / \mathrm{mm}^{2}\right)$ than in the control group 
$\left(2812.7 \pm 395.2\right.$ cells $/ \mathrm{mm}^{2}, \mathrm{P}=0.046$, Fig. 1 Left $)$. In addition, nerve density in the subbasal layer was significantly lower in the DED group $\left(17.1 \pm 6.9 \mathrm{~mm} / \mathrm{mm}^{2}\right)$ than in the control group $\left(24.7 \pm 4.4 \mathrm{~mm} / \mathrm{mm}^{2}, \mathrm{P}<0.001\right.$, Fig. 1 Middle). There was also a significantly higher density of subbasal immune dendritic cells in the DED group $\left(111.7 \pm 137.3 \mathrm{cells} / \mathrm{mm}^{2}\right)$ than in the control group $\left(32.0 \pm 24.4\right.$ cells $/ \mathrm{mm}^{2}, \mathrm{P}=0.002$, Fig. 1 Right $)$.

The central corneal ECD showed statistically significant correlations with the OSDI score $\left(r_{s}=-0.26, P=0.03\right)$, and corneal fluorescein staining $\left(r_{s}=-0.28, P=0.008\right)$.

\section{DISCUSSION}

This cross-sectional controlled study showed that in the moderate to severe DED, there was a significant reduction in central corneal ECD as compared to the age- and gender-matched control group. In addition, ECD showed significant correlation with clinical severity of the disease, as judged by symptoms and corneal fluorescein staining. Therefore, our data indicate that the corneal involvement seen in DED may not be limited to the ocular surface and epithelium.

Although DED-induced molecular and cellular changes in various ocular structures such as lacrimal gland, tear film, conjunctiva, and cornea have been studied extensively, there have been limited data reported on the endothelial cell changes in DED. Interestingly, our study showed a significantly lower central ECD in the DED group compared to that of the control group (Fig. 1 Left). In a study by Erdelyi et $\mathrm{al}^{9}$ on 26 patients suffering from dry eye problems (including 10 with aqueous tear deficiency, 8 with dysthyroid ophthalmopathy, and 8 with chronic lagophthalmos) and 10 normal controls, the ECD in these groups was $2,572 \pm 656 \mathrm{cells} / \mathrm{mm}^{2}, 3,085 \pm 575 \mathrm{cells} / \mathrm{mm}^{2}, 2,573 \pm 467 \mathrm{cells} / \mathrm{mm}^{2}$, and 3,193 $\pm 1,042$ cells $/ \mathrm{mm}^{2}$, respectively. Although they showed a lower ECD in the aqueous tear deficient group than in the controls, the difference did not reach statistical significance, probably due to a small sample size. They also found Fuchs-like lesions at the endothelial layer in 3 out of 8 patients with dysthyroid ophthalmopathy. Reversible corneal endothelial changes in the form of subendothelial dark areas have also been reported in cases with superficial keratopathy such as superficial punctate keratitis, exposure keratopathy, chemical keratopathy and keratoconjunctivitis sicca. ${ }^{21}$ These changes in the density and morphology of the corneal endothelial cells in DED show that the corneal involvement seen in DED may be more extensive than traditionally thought.

In our study, there were significant correlations between ECD and the severity of DED as determined by symptoms (OSDI score) and signs (corneal fluorescein staining). As a correlation may be expected between the clinical severity of DED and the extent of underlying pathophysiologic parameters, our data indicate that the mechanisms involved in causing ocular surface damage, and thus symptoms and signs of DED, may directly or indirectly induce endothelial cell loss.

The mechanisms underlying the endothelial cell changes seen in DED remain to be elucidated. One possible mechanism is that the lower ECD is due to reduced corneal nerves in DED. In the current study, eyes with DED displayed significantly lower subbasal nerve 
density than did those in the control group (Fig. 1 Middle), as has been described previously. ${ }^{7-9,22}$ Lambiase and colleagues ${ }^{18}$ have also reported significantly lower ECD in eyes with neurosurgically-induced neurotrophic keratitis than in the controls, with a significant correlation between the duration of the neurotrophic state and the endothelial loss. In many other ocular conditions, a decrease in density and/or function of both subbasal nerves and endothelium has been shown; these conditions include diabetes, ${ }^{23-26}$ contact lens wear, ${ }^{27-28}$ herpes simplex keratitis, ${ }^{20,29}$ and even pseudoexfoliation syndrome. ${ }^{30}$ In addition, reduced nerve density has also been shown in those conditions with obvious endothelial compromise such as bullous keratopathy ${ }^{31}$ and Fuchs endothelial dystrophy. ${ }^{32,33}$ The presence of a concomitant decrease in nerves and endothelium may implicate a role for corneal nerves in the maintenance of endothelial function and survival. Alternatively, both nerves and endothelial cells may be reduced as a result of a common pathogenic pathway such as inflammation.

DED-associated inflammation may change the corneal microenvironment, causing not only nerve damage but also dysfunction and/or structural damage to endothelial cells.

Inflammation has been established as an important mechanism involved in the pathophysiology of DED. ${ }^{4}$ It is reasonable then to speculate that inflammation in DED may not be limited to the superficial layers, and deeper layers may also be involved, as has been indicated by the involvement of stromal keratocytes in DED. ${ }^{22}$ As inflammation is known to cause endothelial damage, ${ }^{34,35}$ it may be expected that DED-associated inflammation might result in endothelial loss. Although cytological inflammatory markers were not evaluated in our study, the density of subbasal immune dendritic cells, which are an integral part of immune activation, ${ }^{36,37}$ was measured using IVCM. We found significantly higher dendritic cell density in the DED group than in the control group (Fig. 1 Right), as has been reported previously. ${ }^{10,22,38}$ Additional studies will be required to evaluate the possible direct or indirect role of DED-induced inflammation or the possible neurogenic mechanisms involved in the endothelial cell damage seen in DED. In addition to the above-mentioned mechanisms, cellular senescence may also be considered as a possible explanation of reduced ECD in patients with DED. In this case, the accelerated aging process in the susceptible individuals may result in low ECD, low corneal nerves, and DED without any cause-and-effect relationship between them.

It should be noted that this study only included cases with moderate to severe DED with a mean OSDI score of $61.5 \pm 20$, and mean NEI corneal fluorescein staining of 7.0 $\pm 3.4 .{ }^{39} \mathrm{As}$ there was a correlation between the severity of DED and the resultant endothelial loss, there is a possibility that ECD might not be affected in mild cases of DED, which are commonly encountered in clinical practice. Therefore, this endothelial loss may be of greater concern in more severe cases. On the other hand, cases with pre-existing endothelial damage such as those with already low ECD or following intraocular procedures may be affected more by this DED-associated endothelial loss. It is also reasonable to speculate that with treatment of DED, the mechanisms involved in endothelial cell death might be controlled, resulting in prevention of further cell loss. Additional research is necessary to show the effects of DED therapy on endothelial survival and function. 


\section{Acknowledgments}

Funding/Support: NIH K24-EY019098 (Bethesda, Maryland), Falk Medical Research Trust, Massachusetts Eye and Ear Infirmary Foundation (Boston, Massachusetts).

Other Acknowledgments: None.

\section{References}

1. The epidemiology of dry eye disease: report of the Epidemiology Subcommittee of the International Dry Eye WorkShop (2007). Ocul Surf. 2007; 5(2):93-107. [PubMed: 17508117]

2. Lin PY, Tsai SY, Cheng CY, Liu JH, Chou P, Hsu WM. Prevalence of dry eye among an elderly Chinese population in Taiwan: the Shihpai Eye Study. Ophthalmology. 2003; 110(6):1096-1101. [PubMed: 12799232]

3. McCarty CA, Bansal AK, Livingston PM, Stanislavsky YL, Taylor HR. The epidemiology of dry eye in Melbourne, Australia. Ophthalmology. 1998; 105(6):1114-1119. [PubMed: 9627665]

4. The definition and classification of dry eye disease: report of the Definition and Classification Subcommittee of the International Dry Eye WorkShop (2007). Ocul Surf. 2007; 5(2):75-92. [PubMed: 17508116]

5. Davis EA, Dohlman CH. Neurotrophic keratitis. Int Ophthalmol Clin. 2001; 41(1):1-11. [PubMed: 11198136]

6. Bonini S, Rama P, Olzi D, Lambiase A. Neurotrophic keratitis. Eye (Lond). 2003; 17(8):989-995. [PubMed: 14631406]

7. Benitez del Castillo JM, Wasfy MA, Fernandez C, Garcia-Sanchez J. An in vivo confocal masked study on corneal epithelium and subbasal nerves in patients with dry eye. Invest Ophthalmol Vis Sci. 2004; 45(9):3030-3035. [PubMed: 15326117]

8. Benitez-Del-Castillo JM, Acosta MC, et al. Relation between corneal innervation with confocal microscopy and corneal sensitivity with noncontact esthesiometry in patients with dry eye. Invest Ophthalmol Vis Sci. 2007; 48(1):173-181. [PubMed: 17197530]

9. Erdelyi B, Kraak R, Zhivov A, Guthoff R, Nemeth J. In vivo confocal laser scanning microscopy of the cornea in dry eye. Graefes Arch Clin Exp Ophthalmol. 2007; 245(1):39-44. [PubMed: 16874525]

10. Villani E, Magnani F, Viola F, et al. In vivo confocal evaluation of the ocular surface morphofunctional unit in dry eye. Optom Vis Sci. 2013; 90(6):576-586. [PubMed: 23670123]

11. Labbe A, Liang Q, Wang Z, et al. Corneal nerve structure and function in patients with non-sjogren dry eye: clinical correlations. Invest Ophthalmol Vis Sci. 2013; 54(8):5144-5150. [PubMed: 23833066]

12. Rozsa AJ, Beuerman RW. Density and organization of free nerve endings in the corneal epithelium of the rabbit. Pain. 1982; 14(2):105-120. [PubMed: 7177676]

13. Muller LJ, Marfurt CF, Kruse F, Tervo TM. Corneal nerves: structure, contents and function. Exp Eye Res. 2003; 76(5):521-542. [PubMed: 12697417]

14. Marfurt CF, Cox J, Deek S, Dvorscak L. Anatomy of the human corneal innervation. Exp Eye Res. 2010; 90(4):478-492. [PubMed: 20036654]

15. Sigelman SFJ. Mitotic and wound healing activities of the corneal epithelium: effect of sensory denervation. AMA Arch Ophthalmol. 1954; 52(1):46-57. [PubMed: 13170864]

16. You L, Kruse FE, Volcker HE. Neurotrophic factors in the human cornea. Invest Ophthalmol Vis Sci. 2000; 41(3):692-702. [PubMed: 10711683]

17. Koh SW, Yue BY. VIP stimulation of cAMP production in corneal endothelial cells in tissue and organ cultures. Cornea. 2002; 21(3):270-274. [PubMed: 11917175]

18. Lambiase A, Sacchetti M, Mastropasqua A, Bonini S. Corneal changes in neurosurgically induced neurotrophic keratitis. JAMA Ophthalmol. 2013; 131(12):1547-1553. [PubMed: 24158681]

19. Mimura T, Amano S, Fukuoka S, et al. In vivo confocal microscopy of hereditary sensory and autonomic neuropathy. Curr Eye Res. 2008; 33(11):940-945. [PubMed: 19085376] 
20. Hamrah P, Cruzat A, Dastjerdi MH, et al. Corneal sensation and subbasal nerve alterations in patients with herpes simplex keratitis: an in vivo confocal microscopy study. Ophthalmology. 2010; 117(10):1930-1936. [PubMed: 20810171]

21. Brooks AM, Grant G, Gillies WE. Reversible corneal endothelial cell changes in diseases of the anterior segment. Aust N Z J Ophthalmol. 1987; 15(4):283-289. [PubMed: 3435671]

22. Alhatem A, Cavalcanti B, Hamrah P. In vivo confocal microscopy in dry eye disease and related conditions. Semin Ophthalmol. 2012; 27(5-6):138-148. [PubMed: 23163268]

23. Ishida N, Rao GN, del Cerro M, Aquavella JV. Corneal nerve alterations in diabetes mellitus. Arch Ophthalmol. 1984; 102(9):1380-1384. [PubMed: 6236781]

24. Saini JS, Mittal S. In vivo assessment of corneal endothelial function in diabetes mellitus. Arch Ophthalmol. 1996; 114(6):649-653. [PubMed: 8639073]

25. Sudhir RR, Raman R, Sharma T. Changes in the corneal endothelial cell density and morphology in patients with type 2 diabetes mellitus: a population-based study, Sankara Nethralaya Diabetic Retinopathy and Molecular Genetics Study (SN-DREAMS, Report 23). Cornea. 2012; 31(10): 1119-1122. [PubMed: 22357387]

26. Tavakoli M, Petropoulos IN, Malik RA. Corneal confocal microscopy to assess diabetic neuropathy: an eye on the foot. J Diabetes Sci Technol. 2013; 7(5):1179-1189. [PubMed: 24124944]

27. Efron N. Contact lens-induced changes in the anterior eye as observed in vivo with the confocal microscope. Prog Retin Eye Res. 2007; 26(4):398-436. [PubMed: 17498998]

28. Patel SV, McLaren JW, Hodge DO, Bourne WM. Confocal microscopy in vivo in corneas of longterm contact lens wearers. Invest Ophthalmol Vis Sci. 2002; 43(4):995-1003. [PubMed: 11923239]

29. Nagy RM, McFall RC, Sery TW, Nagle BT, McGreevy LM. Scanning electron microscope study of herpes simplex virus experimental disciform keratitis. Br J Ophthalmol. 1978; 62(12):838-842. [PubMed: 737164]

30. Zheng X, Shiraishi A, Okuma S, et al. In vivo confocal microscopic evidence of keratopathy in patients with pseudoexfoliation syndrome. Invest Ophthalmol Vis Sci. 2011; 52(3):1755-1761. [PubMed: 21212178]

31. Al-Aqaba M, Alomar T, Lowe J, Dua HS. Corneal nerve aberrations in bullous keratopathy. Am J Ophthalmol. 2011; 151(5):840-849. [PubMed: 21310389]

32. Ahuja Y, Baratz KH, McLaren JW, Bourne WM, Patel SV. Decreased corneal sensitivity and abnormal corneal nerves in Fuchs endothelial dystrophy. Cornea. 2012; 31(11):1257-1263. [PubMed: 22357383]

33. Schrems-Hoesl LM, Schrems WA, Cruzat A, et al. Cellular and subbasal nerve alterations in early stage Fuchs' endothelial corneal dystrophy: an in vivo confocal microscopy study. Eye (Lond). 2013; 27(1):42-49. [PubMed: 23154490]

34. Elgebaly SA, Forouhar F, Gillies C, Williams S, O'Rourke J, Kreutzer DL. Leukocyte-mediated injury to corneal endothelial cells. A model of tissue injury. Am J Pathol. 1984; 116(3):407-416. [PubMed: 6476078]

35. Rowland FN, Donovan MJ, Lindsay M, Weiss WI, O’Rourke J, Kreutzer DL. Demonstration of inflammatory mediator-induced inflammation and endothelial cell damage in the anterior segment of the eye. Am J Pathol. 1983; 110(1):1-12. [PubMed: 6681582]

36. Barabino S, Chen Y, Chauhan S, Dana R. Ocular surface immunity: homeostatic mechanisms and their disruption in dry eye disease. Prog Retin Eye Res. 2012; 31(3):271-285. [PubMed: 22426080]

37. Stevenson W, Chauhan SK, Dana R. Dry eye disease: an immune-mediated ocular surface disorder. Arch Ophthalmol. 2012; 130(1):90-100. [PubMed: 22232476]

38. Lin H, Li W, Dong N, et al. Changes in corneal epithelial layer inflammatory cells in aqueous teardeficient dry eye. Invest Ophthalmol Vis Sci. 2010; 51(1):122-128. [PubMed: 19628746]

39. Miller KL, Walt JG, Mink DR, et al. Minimal clinically important difference for the ocular surface disease index. Arch Ophthalmol. 2010; 128(1):94-101. [PubMed: 20065224] 


\section{Biographies}

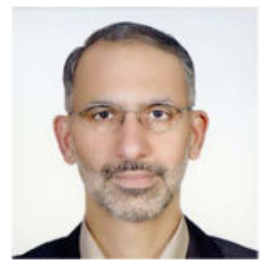

Ahmad Kheirkhah is an Instructor at Harvard Medical School and an Investigator at Massachusetts Eye and Ear Infirmary, Boston, Massachusetts. His main focus of work and research is ocular surface disease, with particular interest in dry eye disease and the role of nerves in corneal health and function. He is an author of numerous peer-reviewed publications in this field.

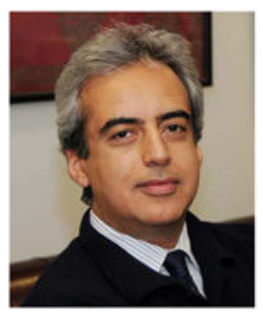

Reza Dana holds the Claes Dohlman Chair in Ophthalmology at Harvard Medical School. He is Director of the Cornea Service at Massachusetts Eye and Ear, Co-Director of the Harvard Medical School Cornea Center of Excellence, Senior Scientist at the Schepens Eye Research Institute, and a member of the Harvard Medical School Committee on Immunology. A graduate of Johns Hopkins and Harvard Universities, he studies the molecular and cellular regulation of corneal and ocular surface immunity. 


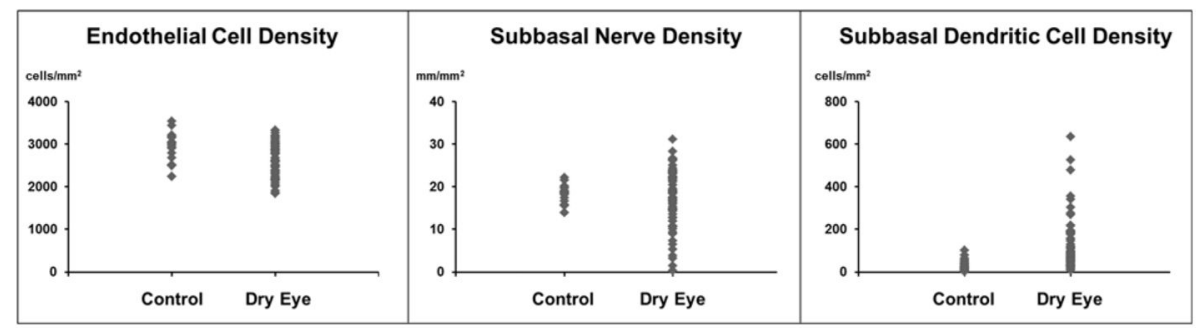

Fig. 1.

Densities of corneal endothelial cells (Left), subbasal nerves (Middle), subbasal immune dendritic cells (Right) in patients with dry eye disease and the age- and gender-matched control group. 